\title{
Diferentes massas de forragem sobre as variáveis morfogênicas e estruturais de azevém anual
}

\author{
Different herbage masses on morphogenetic and structural traits of Italian ryegrass
}

\author{
Anna Carolina Cerato Confortin ${ }^{\mathrm{I}}$ Marta Gomes da Rocha ${ }^{*}$ Juliana Medianeira Machado $^{\mathrm{I}}$ \\ Juliano Roman' Fernando Luiz Ferreira de Quadros ${ }^{I}$ Luciana Pötter $^{I}$
}

\section{RESUMO}

Características morfogênicas e estruturais de azevém (Lolium multiflorum Lam.) foram avaliadas sob pastejo de borregas, em diferentes massas de forragem (MF): "Alta", "Média" e "Baixa", correspondentes a 1800-2000; 1400-1600 e 1000-1200kg ha-1 de matéria seca (MS), respectivamente. O delineamento experimental foi inteiramente casualizado, com três tratamentos e duas repetições de área. O método de pastejo foi de lotação contínua, com número variável de animais. Os dados foram submetidos a análises de correlação e regressão polinomial. A altura do pseudocolmo, o comprimento de lâminas intactas e desfolhadas e o número de folhas em senescência de azevém aumentaram linearmente com a elevação dos valores das massas de forragem. O número de folhas verdes ajustou-se ao modelo de regressão quadrático; o número de folhas em expansão e a densidade populacional de perfilhos não se ajustaram a nenhum modelo de regressão. Em pastagem de azevém, o manejo com massas de forragem dentro da faixa compreendida entre 1.100 e $1.800 \mathrm{~kg} \mathrm{ha}^{-1}$ de MS não provoca alterações nas características morfogênicas dessa gramínea, mas causa diferenças nas características estruturais do dossel. Quando o azevém é manejado com $1.460 \mathrm{~kg} \mathrm{ha}^{-1} \mathrm{de} \mathrm{MS}$, seus perfilhos mantêm maior número de folhas verdes e com $1.800 \mathrm{~kg} \mathrm{ha}^{-1}$ de MS existe maior número de lâminas foliares em senescência e com maior comprimento.

Palavras-chave: borregas, Lolium multiflorum Lam., lotação contínua, perfilhos marcados.

\section{ABSTRACT}

Morphogenetic and structural characteristics of Italian ryegrass (Lolium multiflorum Lam.), utilized by female lambs and managed with different forage masses (FM) were studied. The experimental design was completely randomized, with two area replications and three treatments, consisting of forage masses: "High", "Mean" and "Low", corresponding to 1,800-2,000; 1,400-1,600 and 1,000-1,200kg ha-1 of dry matter (DM), respectively. The grazing method was continuous with variable stocking rate. Data were subjected to correlation analysis and polynomial regression. Pseudo stem's height and length of the intact and defoliated leaf blades and number of senescent leaves of Italian ryegrass increased linearly with the increase of forage mass. Number of green leaves was adjusted to the quadratic regression model, number of leaves in elongation and tiller population density did not adjust to any regression model. Management of Italian ryegrass with forage masses between 1,100 and 1,800kg ha of DM did not cause changes in its morphogenetic characteristics, but causes differences in the structural characteristics of the canopy. When managed with $1,460 \mathrm{~kg} \mathrm{ha}^{-1}$ of DM, tillers of Italian ryegrass maintain greater number of green leaves. Meanwhile, when managed with $1,800 \mathrm{~kg} \mathrm{ha}^{-1}$ of DM it has a higher number of leaf blades in senescence, and leaves with greater length.

Key words: continuous grazing, female lambs, Lolium multiflorum Lam., marked tillers.

\section{INTRODUÇÃO}

As avaliações de respostas morfofisiológicas e morfogênicas das plantas forrageiras são importantes no entendimento e planejamento de estratégias e práticas de manejo. Essas avaliações definem os limites de flexibilidade e uso, tanto de plantas como de animais, na composição de sistemas de produção animal a pasto (DA SILVA \& NASCIMENTO JR., 2007).

'Programa de Pós graduação em Zootecnia, Universidade Federal de Santa Maria (UFSM), 97105-900, Santa Maria, RS, Brasil. E-mail: mgdarocha@gmail.com. *Autor para correspondência 
O azevém anual (Lolium multiflorum Lam.) tem grande importância nos sistemas produtivos pecuários do sul do Brasil e constitui-se na espécie forrageira de estação fria mais utilizada no Rio Grande do Sul (RS). Em função disso, alguns estudos têm sido conduzidos para avaliar a influência de alternativas de manejo na morfogênese dessa espécie. PONTES et al. (2003) avaliaram a influência de alturas do dossel de 5, 10,15 e $20 \mathrm{~cm}$ na morfogênese de azevém anual, utilizado por borregos, e verificaram que, à medida que a altura foi aumentada, foram observados maior taxa de elongação foliar, menor tempo de duração da elongação da folha e maior tamanho final delas. Também em azevém submetido a diferentes métodos e intensidades de pastejo, CAUDURO et al. (2006) observaram que, independentemente de método de pastejo, na intensidade de pastejo baixa (oferta de 2,5 vezes o potencial de consumo de cordeiros), ocorre maior taxa de elongação, menor densidade populacional de perfilhos, maior comprimento e maior número de folhas vivas por perfilho de azevém.

Tanto PONTES et al. (2003) quanto CAUDURO et al. (2006) buscaram relacionar a resposta da planta ao manejo baseado em critérios relacionados à abundância de forragem, os quais, de acordo com HERINGER \& CARVALHO (2002), estão associados à oportunidade do animal colher mais ou menos forragem, de maior ou menor qualidade e, portanto, também estão ligados ao desempenho animal.

A massa de forragem se correlaciona diretamente com a forragem disponível aos animais, constituindo-se, portanto, em um dos critérios mais utilizados e relevantes para o manejo do pastejo. Conforme MANNETJE (2000), o monitoramento da variação da massa de forragem é uma das formas mais efetivas de gerar subsídios para diversos processos de gerenciamento e tomada de decisão sobre o manejo de pastagens.
A massa de forragem pode estar espacialmente disposta em uma forma infinita de combinações de altura e densidade volumétrica, influenciando na quantidade e qualidade da forragem ingerida pelo animal (CARVALHO et al., 2001). Assim, a importância de avaliações que permitam melhor compreender a formação da estrutura do pasto é evidenciada pelo fato de que uma mesma massa de forragem poder ser obtida com diferentes alturas e/ou estruturas e vice-versa. Sendo assim, este trabalho foi conduzido com o objetivo de avaliar a morfogênese e estrutura de azevém anual manejado com diferentes massas de forragem.

\section{MATERIAL E MÉTODOS}

O experimento foi realizado na Universidade Federal de Santa Maria (UFSM), localizada na região fisiográfica da Depressão Central do Rio Grande do Sul (RS), no período de maio a outubro de 2004. O solo é classificado como Argissolo Vermelho distrófico arênico (EMBRAPA, 2006) e sua análise química apresentou os seguintes resultados: $\mathrm{pH}-\mathrm{H}_{2} \mathrm{O}$ : 5,25; índice SMP: 5,75; Argila: $26,5 \mathrm{~m} \mathrm{~V}^{-1}$; $\mathrm{P}: 11,75 \mathrm{mg} \mathrm{L}^{-1}$; $\mathrm{K}$ : $61 \mathrm{mg} \mathrm{L}^{-1}$; MO: $3,1 \mathrm{~m} \mathrm{~V}^{-1}$; $\mathrm{Al}: 0,6 \mathrm{cmol}_{\mathrm{c}} \mathrm{L}^{-1}$; $\mathrm{Ca}: 7,05 \mathrm{cmol}_{\mathrm{c}}$ $\mathrm{L}^{-1}$; $\mathrm{Mg}: 2,95 \mathrm{cmol}_{\mathrm{c}} \mathrm{L}^{-1}$; CTC efetiva: $10,7 \mathrm{cmol}_{\mathrm{c}} \mathrm{L}^{-1}$; saturação de bases: $66,5 \%$ e saturação de $\mathrm{Al}: 8,0 \%$. A região possui clima subtropical úmido (Cfa), conforme classificação de Köppen, e os dados climatológicos referentes ao período experimental foram obtidos na estação meteorológica da UFSM (Tabela 1).

O delineamento experimental foi inteiramente casualizado com três tratamentos e duas repetições de área. Foi avaliada a utilização de três faixas de massas de forragem em azevém anual, pastejado por ovinos: "Baixa", "Média" e "Alta", correspondentes a 1.000$1.200 ; 1.400-1.600$ e $1.800-2.000 \mathrm{~kg} \mathrm{ha}^{-1}$ a de matéria seca (MS), respectivamente.

Tabela 1 - Precipitação pluviométrica mensal $(\mathrm{mm})$ e temperaturas médias $\left({ }^{\circ} \mathrm{C}\right)$ ocorridas e esperadas (normal climatológica), durante o período experimental. Santa Maria - RS.

\begin{tabular}{|c|c|c|c|c|}
\hline \multirow{2}{*}{ Meses } & \multicolumn{2}{|c|}{----Temperatura ambiente $\left({ }^{\circ} \mathrm{C}\right)$------- } & \multirow[b]{2}{*}{ Ocorrida } & \multirow[b]{2}{*}{ Esperada } \\
\hline & Ocorrida & Esperada & & \\
\hline Maio & 16,0 & 12,0 & 129,1 & 90,6 \\
\hline Junho & 12,9 & 15,6 & 144,0 & 82,0 \\
\hline Julho & 13,5 & 12,9 & 148,6 & 72,5 \\
\hline Agosto & 14,6 & 15,2 & 137,4 & 85,4 \\
\hline Setembro & 16,2 & 18,3 & 153,6 & 96,3 \\
\hline Outubro & 18,8 & 18,5 & 145,9 & 119,7 \\
\hline
\end{tabular}


A área experimental utilizada constituiu-se de seis piquetes de aproximadamente 0,23 ha cada. $O$ solo foi preparado com duas gradagens e a adubação e a semeadura foram realizadas a lanço, no dia $21 / 05 /$ 2004. Foram utilizados $250 \mathrm{~kg} \mathrm{ha}^{-1} \mathrm{da}$ fórmula 5-20-20 (N-P-K) e $60 \mathrm{~kg} \mathrm{ha}^{-1}$ de semente de azevém. Em cobertura, foram utilizados $75 \mathrm{~kg} \mathrm{ha}^{-1}$ de nitrogênio, na forma de uréia, fracionados em duas aplicações iguais (13/07 e 03/09). O período de utilização da pastagem foi de $17 /$ 07 a 08/10/2004, totalizando 85 dias de pastejo.

Os animais experimentais foram três borregas cruzas Texel x Ile de France por repetição, com idade, peso vivo e escore de condição corporal médios, no início do período experimental, de: 11 meses, $31,2 \pm 2,8 \mathrm{~kg}$ e $2,7 \pm 0,1$ pontos, respectivamente. Todos os animais tiveram acesso irrestrito à água e sal comum.

Utilizou-se o método de pastejo com lotação contínua e as massas de forragem pretendidas, de acordo com os tratamentos estabelecidos, foram obtidas por meio de ajustes na taxa de lotação. O pastejo foi diurno e os animais permaneceram em abrigos durante o período noturno, para evitar a perda de animais experimentais por abigeato e/ou ataque de predadores.

A massa de forragem foi determinada, em intervalos de 14 dias, por meio do método de estimativa visual direta com dupla amostragem (MANNETJE, 2000), com 20 estimativas visuais e cinco cortes, em cada piquete. A partir das amostras provenientes dos cortes, foram feitas duas subamostras: uma utilizada para a determinação do teor de MS do pasto e outra para a determinação da participação dos seus componentes estruturais.

A participação dos componentes estruturais do pasto foi obtida pela separação manual da amostra, coletada em lâmina foliar, pseudocolmo (bainha foliar + colmo), material morto e inflorescência. Outras espécies eram praticamente inexistentes na área. Posteriormente, o material foi seco em estufa de circulação forçada de ar, a $55^{\circ} \mathrm{C}$, por 72 horas, e pesado. A massa de componentes estruturais ( $\left.\mathrm{kgha}^{-1} \mathrm{de} \mathrm{MS}\right)$ foi obtida por meio do produto entre a massa de forragem e a participação percentual de cada componente. A razão entre a massa de lâminas foliares e de pseudocolmos (colmo + bainha foliar) resultou na relação lâmina: pseudocolmo.

Em cada piquete, a altura do dossel foi medida, semanalmente, em 30 pontos aleatórios (ROMAN et al., 2007). Nesses locais, foram escolhidos cinco perfilhos representativos da população do azevém na massa de forragem correspondente, nos quais foi medida a altura do pseudocolmo. Essa altura foi considerada como a distância, em cm, desde o solo até a lígula da última folha completamente expandida do perfilho. A densidade populacional de perfilhos foi determinada nos dias 16/08,12/09 e 09/10, por meio da contagem dos perfilhos vivos de azevém, existentes em cinco quadrados de $0,0625 \mathrm{~m}^{2}$ de área, em cada piquete.

A taxa de lotação para manter as massas de forragem (MF) desejadas foi realizada conforme HERINGER \& CARVALHO (2002). O número de borregas ha/dia foi calculado pela razão entre a taxa de lotação e o peso médio dos animais-teste, durante o período experimental, que foi de $40,0 \mathrm{~kg}$. A soma térmica do período foi calculada pela equação: soma térmica $=\sum_{\mathrm{i}=1}^{\mathrm{n}}(\mathrm{Tm}-\mathrm{Tb})$, em que $\mathrm{Tm}=$ temperatura média diária $\left({ }^{\circ} \mathrm{C}\right) ; \mathrm{Tb}=$ temperatura base (RUSSELLE et al., 1984). O valor considerado como temperatura base de crescimento para as espécies de estação fria é de $5^{\circ} \mathrm{C}$ (Cooper \& Tainton, 1968 apud QUADROS et al., 2005).

Para a avaliação das variáveis morfogênicas e estruturais, utilizou-se a técnica de "perfilhos marcados" (CARRÈRE et al., 1997). Em cada piquete, foram marcados 20 perfilhos de azevém, com fios telefônicos coloridos. As avaliações foram feitas com intervalos de três ou quatro dias, no período compreendido entre $06 / 08$ a 04/10. O comprimento de lâminas foliares expandidas (com lígula visível) e em expansão foi medido em $\mathrm{cm}$. Também foi observada a condição das folhas: em senescência ou não, intacta ou desfolhada. As folhas expandidas foram medidas a partir de sua lígula, enquanto que as em expansão, a partir da lígula da última folha completamente expandida. Nas folhas em senescência, foi medida apenas a porção verde da lâmina foliar.

As variáveis originadas foram: comprimento de lâminas foliares intactas e desfolhadas, número de folhas intactas e desfolhadas, número de folhas em expansão e em senescência e número total de folhas verdes. As taxas de elongação e senescência, $\mathrm{em} \mathrm{cm} /$ graus dia foram calculadas por meio da razão entre a elongação ou senescência média do perfilho entre duas avaliações consecutivas, e a soma térmica acumulada no mesmo período. A taxa de aparecimento foliar foi calculada pelo valor do coeficiente angular da regressão entre o número de folhas produzidas por um perfilho e a soma térmica acumulada no período correspondente. $\mathrm{O}$ filocrono foi considerado como o valor inverso da taxa de aparecimento foliar. Por meio do produto do filocrono com o número de folhas verdes por perfilho, obteve-se a duração de vida das folhas e, por meio produto entre o filocrono e o número de folhas em elongação por perfilho, obteve-se a duração da elongação.

Para análise estatística, foram consideradas as massas de forragem médias mantidas nas unidades experimentais: 1.190,9kg ha-1 MS ("Baixa", repetição 1); $1.136,8 \mathrm{~kg} \mathrm{ha}^{-1} \mathrm{MS}$ ("Baixa", repetição 2); $1.375 \mathrm{~kg} \mathrm{ha}^{-1}$ MS ("Intermediária", repetição 1); 1.359,2kg ha-1 MS 
("Intermediária", repetição 2); $1.739,1 \mathrm{~kg} \mathrm{ha}^{-1} \mathrm{MS}$ (“Alta”, repetição 1) e $1.556,0 \mathrm{~kg} \mathrm{ha}^{-1} \mathrm{MS}$ ("Alta", repetição 2). Os dados foram submetidos a análises de correlação linear de Pearson e regressão polinomial em função das massas de forragem observadas. Quando ambos os modelos de regressão, linear e quadrático, foram significativos, foi utilizado o modelo com o maior valor de coeficiente de determinação. Para identificar as variáveis independentes com influência sobre as variáveis estruturais de azevém anual, foi utilizado o procedimento Stepwise, sendo desconsideradas as variáveis com coeficientes de determinação $\left(R^{2}\right)$ inferiores a 0,50. Utilizou-se o pacote estatístico SAS, versão 8.2 (2001), a 10\% de probabilidade.

\section{RESULTADOS E DISCUSSÃO}

A massa de lâminas foliares $\left(\mathrm{Y}=212,87+0,44212 \mathrm{x} ; \mathrm{P}=0,034 ; \mathrm{R}^{2}=0,72\right)$ e de colmos $(\mathrm{Y}=-$ $\left.193,42+0,40643 \mathrm{x} ; \mathrm{P}=0,014 ; \mathrm{R}^{2}=0,82\right)$, a altura do dossel $\left(\mathrm{Y}=-2,04+0,01232 \mathrm{x} ; \mathrm{P}=0,005 ; \mathrm{R}^{2}=0,88\right)$ e as ofertas de forragem $\left(\mathrm{Y}=0,23+0,011 \mathrm{x} ; \mathrm{P}=0,020 ; \mathrm{R}^{2}=0,78\right)$ e de lâminas foliares $\left(\mathrm{Y}=-1,15+0,0083 \mathrm{x} ; \mathrm{P}=0,050 ; \mathrm{R}^{2}=0,65\right)$ aumentaram linearmente com a elevação dos valores de massa de forragem, enquanto que a taxa de lotação ( $\mathrm{Y}=32,30$ $\left.0,01007 \mathrm{x} ; \mathrm{P}=0,057 ; \mathrm{R}^{2}=0,64\right)$ foi reduzida com o aumento da massa de forragem. Esses dados estão publicados e discutidos em ROMAN et al. (2007).

A utilização de diferentes massas de forragem no manejo de azevém anual não resultou em alterações em suas características morfogênicas. As taxas de aparecimento $\left(0,0067 \pm 0,0018\right.$ folhas graus-dia $\left.{ }^{-1}\right)$, elongação $\left(0,06 \pm 0,01 \mathrm{~cm}\right.$ graus- dia $\left.^{-1}\right)$, senescência foliar $\left(0,11 \pm 0,03 \mathrm{~cm}\right.$ graus-dia $\left.{ }^{-1}\right)$, o filocrono $(195,03 \pm 49,81$ graus-dia $\left.^{-1}\right)$, a duração de vida das folhas $(725,29 \pm 172,67$ graus-dia) e a duração da elongação $(311,28 \pm 56,56$ graus-dia) não se ajustaram $(\mathrm{P}>0,1)$ a nenhum modelo de regressão polinomial.

PONTES et al. (2003), avaliando morfogênese de azevém sob lotação contínua, também não observaram efeito de alturas de manejo sobre a taxa de aparecimento foliar de azevém anual, que correspondeu a um filocrono de 166,0 \pm 6 graus-dia. Os valores de filocrono observados no presente experimento estão próximos aos 179,0 graus-dia relatados por GONÇALVES \& QUADROS (2003), em pastagem de azevém adubada com $180 \mathrm{~kg} \mathrm{ha}^{-1}$ de nitrogênio.

A semelhança na taxa de aparecimento foliar de azevém anual nas diferentes massas de forragem pode ser explicada por que essa variável, dentre as características morfogênicas, é a mais dependente da temperatura e, portanto, sofre menos influência do manejo. Além disso, mesmo nas menores massas de forragem, os perfilhos possuíam folhas intactas e, de acordo com DAVIES (1974), a taxa de aparecimento foliar praticamente não é afetada por uma desfolha que remova apenas algumas folhas por perfilho, mas é diminuída quando todas as folhas do perfilho são removidas.

O valor médio observado para a duração de vida das folhas de azevém anual foi $102,2 \%$ superior aos 358,7 graus-dia encontrados por PONTES et al. (2003). Os menores valores relatados por esses autores são explicados pela maior velocidade de surgimento das folhas, pois o número médio de folhas verdes, mantidas em cada perfilho, foi semelhante ao número observado no presente experimento.

O número de folhas vivas e em expansão por perfilho não se ajustaram $(\mathrm{P}>0,10)$ a nenhum modelo de regressão, indicando que, quando manejado com massas de forragem variando entre 1.100 a $1.800 \mathrm{~kg}$ ha $^{-1}$ de MS, o azevém anual mantém, em média, 4,33 folhas vivas e 1,63 em expansão por perfilho.

As diferentes massas de forragem provocaram alterações nas características estruturais do dossel. $\mathrm{O}$ número de folhas verdes se ajustou ao modelo de regressão quadrática $(\mathrm{P}=0,045$; Figura $1 \mathrm{~A})$, sendo que a massa de forragem de $1.460 \mathrm{~kg} \mathrm{ha}^{-1}$ de MS permitiu a manutenção de um maior número de folhas verdes por perfilho. Já o número de folhas em senescência por perfilho aumentou linearmente com a elevação das massas de forragem ( $\mathrm{P}=0,04$; Figura 1A). Essa variável ajustou-se ao modelo de regressão múltipla $\left(\mathrm{P}=0,04 ; \mathrm{R}^{2}=0,69\right)$ : número de folhas em senescência=-3,099+0,6451 comprimento da lâmina desfolhada, em que $69 \%$ da variação total no número de folhas em senescência de azevém foram explicadas pelo comprimento de lâmina desfolhada.

Isso ocorreu porque a taxa de lotação diminuiu linearmente com o aumento da massa de forragem e o consumo diário de forragem por borrega permaneceu constante (ROMAN et al., 2007). Assim, como as lâminas foliares permanecem verdes por período fixo, quanto maior for o comprimento da lâmina desfolhada, ou seja, quanto menor for a remoção de lâminas por perfilho, proporcionalmente, será maior o número das lâminas que entram em senescência.

A altura do pseudocolmo $(\mathrm{P}=0,032)$ e o comprimento de lâminas intactas $(\mathrm{P}=0,008)$ e desfolhadas $(\mathrm{P}=0,060)$ de azevém anual aumentaram linearmente com a elevação dos valores de massa de forragem (Figura 1B). Os menores valores de pseudocolmo encontrados quando o azevém foi manejado com massas de forragem inferiores, conforme sugerido por PONTES et al. (2003), podem representar uma resposta plástica do azevém à maior frequência e severidade das desfolhações nas menores massas de forragem. 


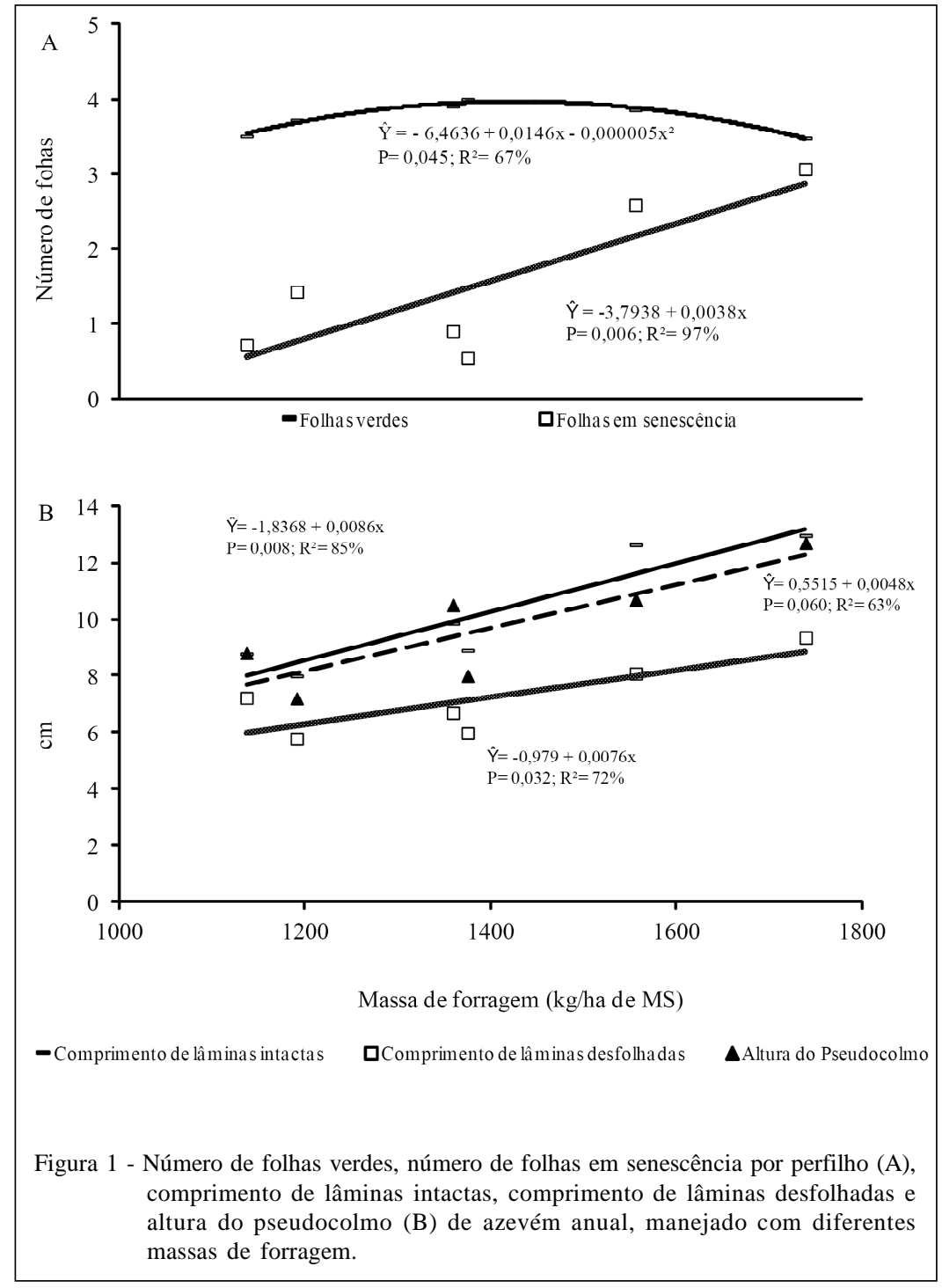

Os valores superiores observados de comprimento de lâmina intacta se devem principalmente às maiores alturas de pseudocolmo, ocorridas sob as maiores massas de forragem. Isso ocorre porque o aparecimento da folha corresponde à cessação da multiplicação celular, após a qual existe apenas a fase de expansão celular e, por isso, a altura do pseudocolmo determina o número de células e, consequentemente, $o$ comprimento da lâmina, para determinadas condições de crescimento (DURU \& DUCROCQ, 2000). Essa ligação entre a altura do pseudocolmo e o comprimento das lâminas foliares também é ilustrada pelo modelo de regressão múltipla $\left(\mathrm{P}=0,003 ; \mathrm{R}^{2}=0,98\right)$ : comprimento da lâmina intacta $=-3,25471+0,00833$ massa de lâminas foliares + 0,67759 altura de pseudocolmo, em que a massa de lâminas foliares e a altura do pseudocolmo originam 15,18 e $82,65 \%$ da variação total no comprimento de lâmina intacta.

O comprimento da lâmina desfolhada de azevém ajustou-se ao modelo de regressão múltipla $\left(\mathrm{P}=0,001 ; \mathrm{R}^{2}=0,99\right)$ : comprimento da lâmina desfolhada $=$ 17,49309-0,43722 taxa de lotação - 1,41930 número de folhas em expansão, sendo que a taxa de lotação e o número de folhas em expansão determinaram 94,93 e $3,85 \%$ da variação total no comprimento de lâmina desfolhada de azevém, respectivamente.

Observa-se que, para a manutenção de maiores massas de forragem, há redução linear no número de borregas ha ${ }^{-1} \mathrm{e}$, como sob lotação contínua, a frequência de desfolha é dependente da taxa de 
lotação (LEMAIRE \& CHAPMAN, 1996). Assim, mesmo que cada borrega desfolhe o azevém anual com a mesma intensidade, nas maiores massas de forragem, provavelmente, a cordeira demorará mais para desfolhar a mesma lâmina, resultando em lâminas desfolhadas com maior comprimento final.

A densidade populacional de perfilhos não se ajustou $(\mathrm{P}>0,10)$ a nenhum modelo de regressão e seu valor médio foi de 2.919,3 $\pm 648,6$ perfilhos $\mathrm{m}^{-2}$. A semelhança entre a taxa de aparecimento foliar nas diferentes massas de forragem provavelmente tenha resultado em densidades populacionais de perfilhos também semelhantes. Isso porque a taxa de aparecimento foliar determina o potencial de gemas e de ocupação de sítios, que juntos determinam a taxa de aparecimento de perfilhos (DAVIES, 1974). O valor observado para densidade de perfilhos é 36,73\% inferior ao relatado por PONTES et al. (2003), de 4.614,4 perfilhos $\mathrm{m}^{-2}$ e $20,77 \%$ inferior aos $3.684,8$ perfilhos $\mathrm{m}^{2}$ encontrados por CAUDURO et al. (2006). Essa diferença pode ser atribuída à adubação nitrogenada, $75 \mathrm{~kg} \mathrm{ha}^{-1}$ de nitrogênio, bastante inferior à utilizada por esses autores $\left(150 \mathrm{~kg} \mathrm{ha}^{-1}\right)$.

$\mathrm{O}$ índice de área foliar do pasto e, consequentemente, sua capacidade de interceptar e fornecer energia para as funções de crescimento, absorção de água e nutrientes pelas raízes é determinado, conforme DAVIES (1993), pela densidade populacional de perfilhos, juntamente com o número de folhas vivas por perfilho e com o tamanho das folhas. A manutenção do azevém anual com massas de forragem em torno de $1.800 \mathrm{~kg} \mathrm{ha}^{-1}$ de MS, provavelmente, resulta em uma capacidade superior de interceptação luminosa em função do maior comprimento de lâminas foliares, pois a densidade populacional de perfilhos e número de folhas vivas por perfilho foram semelhantes nas diferentes massas de forragem.

\section{CONCLUSÃO}

O manejo de azevém (Lolium multiflorum Lam.) com massas de forragem variando entre $1.100 \mathrm{e}$ $1.800 \mathrm{~kg} \mathrm{ha}^{-1}$ de MS não provoca alterações nas características morfogênicas dessa gramínea. Quando manejado com massas de forragem em torno de $1.460 \mathrm{~kg}$ ha ${ }^{-1}$ de MS, o azevém anual mantém maior número de folhas verdes por perfilho.

\section{REFERÊNCIAS}

CARRÈRE, P. et al. Tissue turnover within grass-clover mixed swards grazed by sheep. Methodology for calculating growth, senescence and intake fluxes. Journal of Applied Ecology, v.34, n.2, p.333-348, 1997.
CARVALHO, P.C.F. et al. Importância da estrutura da pastagem na ingestão e seleção de dietas pelo animal em pastejo. In: MATTOS, W.R.S.et al. (Eds.). A produção animal na visão dos brasileiros. Piracicaba: Fundação de Estudos Agrários Luiz de Queiroz, 2001. p.853-871.

CAUDURO, G. et al. Variáveis morfogênicas e estruturais de azevém anual (Lolium multiflorum Lam.) manejado sob diferentes intensidades e métodos de pastejo. Revista Brasileira de Zootecnia, v.35, n.4, p.1298-1307, 2006. Disponível em: 〈http://www.scielo.br/pdf/rbz/v35n4/07.pdf〉. Acesso em: 03 out. 2011. doi: 10.1590/S151635982006000500007 .

DA SILVA S.C.; NASCIMENTO J.R. Avanços na pesquisa com plantas forrageiras tropicais em pastagens: características morfofisiológicas e manejo do pastejo. Revista Brasileira de Zootecnia, v.36, supl. esp, p.121-138, 2007. Disponível em: 〈http://www.scielo.br/pdf/rbz/v36s0/14.pdf>. Acesso em: 03 out. 2011. doi: 10.1590/S1516-35982007001000013.

DAVIES, A. Leaf tissue remaining after cutting and regrowth in perennial ryegrass. Journal of Agricultural Science, v.82, n.1, p.165-172, 1974. Disponível em: <http://journals.cambridge.org/ abstract_S0021859600050334>. Acesso em: 10 set. 2010. doi: $10.1017 / \mathrm{S} 0021859600050334$

DAVIES, A. Tissue turnover in the sward. In: DAVIES, A. et al. (Eds.). Sward measurement handbook. London: British Grassland Society, 1993. p.183-216.

DURU, M.; DUCROCQ, H. Growth and senescence of the successive grass leaves on a tiller ontogenic development and effect of temperature. Annals of Botany, v.85, n.5, p.635643, 2000. Disponível em: <http://aob.oxfordjournals.org/ content/85/5/635.full.pdf >. Acesso em: 13 out. 2011. doi: 10.1006/anbo.2000.1116

EMBRAPA. Centro Nacional e Pesquisa em Solos. Sistema brasileiro de classificação de solos. Brasilia: EmbrapaSPI; Rio de Janeiro: Embrapa-Solos, 2006. 306p.

GONÇALVES, E.N.; QUADROS, F.L.F. Características morfogênicas de azevém (Lolium multiflorum Lam.) sob pastejo em sistemas intensivos de utilização. Ciência Rural, v.33, n.6, p.1129-1134, 2003. Disponível em: <http://www.scielo.br/ pdf/cr/v33n6/a20v33n6.pdf>. Acesso em: 13 out. 2011. doi: 10.1590/S0103-84782003000600020.

HERINGER, I.; CARVALHO, P.C.F. Ajuste da carga animal em experimentos de pastejo: uma nova proposta. Ciência Rural, v.32, n.4, p.675-679, 2002. Disponível em: <http:// www.scielo.br/pdf/cr/v32n4/a21v32n4.pdf $>$. Acesso em: 13 out. 2011. doi: $10.1590 / \mathrm{S} 010384782002000400021$.

LEMAIRE, G.; CHAPMAN, C. Tissue flows in grazed plant communities. In: HODGSON, J.; ILLIUS, A.W. (Ed.). The ecology and management of grazing systems. Guilford: CAB International, 1996. p.3-36.

MANNETJE t', L. Measuring biomass of grassland vegetation. In: _____.; JONES, R.M. (Eds.). Field and laboratory methods for grassland and animal production research. Cambridge: CABI, 2000. p.151-178.

PONTES, L.S. et al. Variáveis morfogênicas e estruturais de azevém anual (Lolium multiflorum Lam.) manejado em 
diferentes alturas. Revista Brasileira de Zootecnia, v.32, n.4, p.814-820, 2003. Disponível em: <http://www.scielo.br/ pdf/rbz/v32n4/17857.pdf >. Acesso em: 13 out. 2011. doi: 10.1590/S1516-35982003000400005.

QUADROS, F.L.F. et al. Morfogênese de Lolium multiflorum Lam. E Paspalum urvillei Steud. sob níveis de adubação de fósforo e potássio. Ciência Rural, v.35, n.1, p.181-186, 2005. Disponível em:<http://www.scielo.br/pdf/cr/v35n1/ a29v35n1.pdf $>$. Acesso em: 13 out. 2011. doi: 10.1590/S010384782005000100029

ROMAN, J. et al. Comportamento ingestivo e desempenho de ovinos em pastagem de azevém anual (Lolium multiflorum Lam.) com diferentes massas de forragem. Revista Brasileira de Zootecnia, v.36, n.4, p.780-788, 2007. Disponível em:〈http://www.scielo.br/pdf/rbz/v36n4/05.pdf >. Acesso em: 13 out. 2011. doi: 10.1590/S1516-35982007000400005.

RUSSELLE, M.P. et al. Growth analysis based on degree days. Crop Science, v.24, n.1, p.28-32, 1984. Disponível em: <https://www.crops.org/ publications/search?search\%5B-3\%5D=\&search Type\%5B$3 \% 5 \mathrm{D}=$ Any\&search $\% 5 \mathrm{~B}-2 \% 5 \mathrm{D}=\mathrm{RUSSELLE} \&$ searchFields $\% 5 \mathrm{~B}$ $2 \% 5 \mathrm{D} \% 5 \mathrm{~B}$ Author $\% 5 \mathrm{D}=$ Author\&searchType $\% 5 \mathrm{~B}-2 \% 5 \mathrm{D}=$ Phrase \& search $\% 5 \mathrm{~B}-1 \% 5 \mathrm{D}=$ Growth+analysis+based+on+degree+days \&searchFields\%5B-1\%5D\%5BTitle\%5D=Title\&searchType\%5B$1 \% 5 \mathrm{D}=$ Phrase $\&$ volume $=24 \&$ issue $=1 \&$ year $=1984 \&$ first page $=\&$ search $\% 5 \mathrm{~B} 0 \% 5 \mathrm{D}=>$. Acesso em: 25 set.2012. doi:10.2135/ cropsci1984.0011183X002400010007x.

SAS INSTITUTE. Statistical analysis system user's guide. Version 8.2. Cary, 2001. 943p. 